\title{
The contemporary factors shaping the professional identity of occupational therapy lecturers \\ Professional identity of occupational therapy lecturers
}

1. Dr. John O'Shea, Senior Lecturer in Occupational Therapy, Coventry University, UK

2. Prof. Simon McGrath, UNESCO Chair in the Political Economy of Education, Associate Head: School of Education, University of Nottingham, UK

Corresponding author: Dr. John O'Shea, Coventry University, Priory Street, Coventry, CV1 5FB. Email: john.oshea@coventry.ac.uk

\section{Abstract:}

\section{Introduction}

The contemporary factors of neoliberalism and evidence based practice (EBP) have implications for professional autonomy and values, education and training, ways of working and construction of knowledge. Occupational therapy lecturers are at the interface between student education and professional practice and therefore have unique insights into the way in which these factors are shaping their professional identity and that of the profession.

\section{Method}

Nine narrative inquiry focused interviews of occupational therapy lecturers from two universities were carried out. Data was interpreted through a Bourdieusian lens, of professional habitus, and analysed thematically.

\section{Findings}

The main factors influencing occupational therapy lecturer identity were noted to be relationships between professional identity and artistry; the professional body of knowledge and language; evidencing practice, neoliberalism and changes to teaching and learning.

\section{Conclusion}


The structural factors of neoliberalism, EBP and associated policies are influencing the occupational therapy professional habitus and in turn occupational therapy lecturers' professional identity. An effective critique of these structural factors is required to maintain the profession's values and artistry and the knowledge upon which occupational therapy lecturers' identity is formed and their approaches to teaching and learning are based.

\section{Key words:}

Professional identity

Neoliberalism

Evidence based practice 


\section{Introduction}

Occupational therapy as a profession, which by extension includes occupational therapy lecturers, has always struggled with its professional identity. The reasons for this are many but in this article it has been identified that there are particular uncertainties about the way in which practice can and should be evidenced and an emerging body of evidence within occupational science underpinning both academic and clinical practice. Central to these is the interplay between evidence based practice (EBP) and professional artistry and the way in which the occupational therapy lecturers negotiate a path between the neoliberal influences on contemporary working and their professional values (Molineux 2011; Turner 2011; Kinsella and Whitford 2009; Clouston and Whitcombe 2008).

This has implications for those who teach occupational therapy and for pedagogical approaches to student learning. This research attempts to draw attention to complex issues by understanding the views of occupational therapy lecturers on these contemporary factors which are shaping their professional identity.

Neoliberalism is driving changes to health and social care policy in the UK and is therefore one of the main structural influences on professionalism and professional identity. It has been the predominant global economic force since the 1980s, championed by the governments of Margaret Thatcher in the UK and Ronald Reagan in the USA (Paton 2014). Although evidence based practice, it has been argued, offers a more rigorous professional approach, it has been critiqued as part of the wider neoliberal move, favouring positivist ways of constructing knowledge that are in sympathy with target driven policy-making and a decentering of professional autonomy within a managerialist culture, undermining more qualitative ways of knowing (Hammersley 2013; Paton 2013; Gabbay and Le May 2011).

Occupational therapy lecturers' professional identity is constructed within this broader political, professional and academic context within which their practice occurs. The contemporary factors discussed have implications for both occupational therapists and occupational therapy 
lecturers, however, it is lecturers' practice which extends out of their identity as occupational therapists which was a focus of this research rather than on the tension between academic and clinical practitioner identities.

In doing this occupational therapy lecturer professional identity was explored from a Bourdieusian perspective of professional habitus. Bourdieu relates habitus as the allencompassing contextualised and ritualised space we inhabit (Bourdieu 1998;1990; Maton 2012). It is a space that is made up of manifold implicit and explicit ways of doing and expressing oneself and which carries with it different types of capital e.g., social, cultural, economic and professional. The habitus therefore is not a fixed cultural and social set of actions within a particular time and place but spaces and environments that are dynamic places of enculturation inhabited and changed by those living and acting within them (Maton 2012). It structures the individual's ways of doing but is also structured by those participants as reflexive individuals.

Therefore the aim of this research is to bring a unique perspective on, and to understand the way in which, contemporary factors of neoliberalism, EBP and emerging disciplinary knowledge discourses are structuring occupational therapy lecturer professional identity. It highlights how this identity is shaped within an occupational therapy professional habitus, and what this means for approaches to teaching and learning of students.

\section{Literature Review}

\section{Neoliberalism and Evidence Based Practice (EBP)}

The neoliberal agenda has been central to NHS reforms, increasing the presence of the markets whilst replacing professional values with a 'pick and mix' approach to utilising and commoditising skills and competencies (Clouston 2014; Paton 2014; Hammersley 2013; Copnell 2010). This continuing shift towards marketisation of health and social care services currently provided by the NHS or local authorities portrays these policy changes as rational approaches to economic management (BMA 2016; Patton 2014). It is also suggested by Speed and Gabe 
(2013) that the decentralised State leads to increased state regulation and decreased professional autonomy as the focus shifts from one of professional values to marketisation and managerialism. The commoditising of the professions such as occupational therapy runs in parallel with an EBP movement and the disempowerment of health professionals (Speed and Gabe 2013; Sullivan 2000) derived out of the relationship between neoliberalism and externally derived competencies and regulation. Although it has been argued that some professional groups have held too much power and are not always representative of the populations they serve (Dingwall 2008), it has also been argued that the loss of professional agency will lead to a decrease in the ability of professions, such as occupational therapy, to challenge policy that runs contrary to the profession's values whilst simultaneously decentring professional agency, knowledge and skills required for a cohesive professional identity (Clouston and Whitcombe 2008; Copnell 2010). This can result in a tension between more nuanced areas of professional practice that revolve around 'patient-centeredness' and 'outcomes based practice' and drive for 'efficiencies' (Bell et al 2015:3).

In responding to these neoliberal pressures, it is suggested that the occupational therapy curriculum taught to students within higher education should promote students' ability to critique neoliberalism and the profession in general should be engaged in this critique (Thibeault 2006; Farias and Rudman,2016; Hocking 2014). Frank (2012) agrees that occupational therapists need to critique social issues and notes that, as occupational science emerges as a discipline, its focus is increasingly on developing a critical discourse on occupational justice and related concepts. However, Frank is not completely dismissive of neoliberalism and suggests that some opportunities have arisen from this which have prompted the development of 'transnational advocacy networks' now enabling global collaborations.

It is also noted that the increasing role of the market within health and social care provision provides opportunities for the profession to sell its services. The focus on 'selling' occupational therapy is resulting in a shift in the teaching and learning of students with an emphasis within occupational therapy curricula on leadership and entrepreneurial business focused skills (Clouston and Whitcombe 2008; Turner 2011) with occupational therapists increasingly employed within the third and private sectors. Whilst this offers benefits, there are concerns 
that occupational therapists are being encouraged to accept the neoliberal discourse as normative and a 'natural and rational' approach without any critique of what this actually means (Kinsella and Whiteford 2009; Wilding and Whiteford 2008; Paterson 2005 et al).

There is also a tension between different ways of knowing. The interpretivist turn seeking to put human experience at the centre of knowledge and to reject reductionism has been embraced by some in the field (Kinsella and Whiteford 2009; Crotty 1998). Hocking (2008) notes the ontological leanings of occupational therapy towards romanticism and the therapeutic use of craft as subjective and transformative processes. She highlights the attempts to reclaim some of the art of the occupational therapist as located within a body of knowledge which values different ways of knowing and subjective experience. Kinsella and Whiteford (2009) also suggest that the growth of EBP is a rejection of the interpretivist turn (which seeks to critique hegemonic power) in favour of reductionist and standardised approaches to the management and delivery of health and social care. It is argued, therefore, that neoliberalism and EBP and their influence on the types of knowledge produced are pervasive and are having an influence on the professional habitus of professions such as occupational therapy.

\section{Professional habitus and identity}

Professional habitus has been discussed by several authors as a way of understanding how professional identity is structured by types of knowledge and practices. O'Conner (2007), in nursing education and training, locates professional habitus as central to identity formation in the negotiation of roles within the 'apprenticeship' models. Artaraz (2006) understands the problems of an emerging professional habitus of Connexions workers, made up of a range of social work type professions, and the bureaucratic structures through which habitus is being formed and mismatches created between existing professional habitus and managerial expectations which require an element of integration between old and new professional identities.

However the influences on occupational therapy lectures' professional identity in relation to their professional habitus and broader professional values are not prevalent in the literature. There is, though, some exploration of occupational therapists' transition into academia by Carra 
et al (2017) and Fortune et al (2016). They mainly focus on the tensions between moving from a clinical to an academic identity and how this can be successfully navigated through a reflexive process which draws on doing, being, becoming. Fortune et al, however, do note that some of these tensions arise from the target culture of the 'neoliberal university' which demands academic outputs but might not support the personal journey of 'Gowning Scholarship'. Frank (2012) has also commented on the formation of occupational science as an academic discipline and its relationship with occupational therapy practice which highlights, somewhat uniquely, the dual role of academics and clinical practitioners which potentially brings about different professional identities.

Neoliberalism and the EBP movement are key factors in the shaping of professional habitus and these are in tension with the values of professions such as occupational therapy and are therefore of interest to occupational therapy lecturers and similar professional groups. However, what this means for OT lecturer identity, their practice and approaches to teaching and learning requires further understanding.

\section{Methods}

Interview data was gathered using a qualitative methodology of narrative inquiry and analysed thematically (see tables two and three). Narrative inquiry has a long tradition within qualitative research which brings to the fore what is inherent within interviews (Riessman 2008). The interpretation of data was also informed by a theoretical perspective based on a Bourdieusian lens of professional habitus, locating the interpretive process within a credible theoretical framework. The methods used are clear and consistent with the conventions of qualitative research and enhance the overall trustworthiness of the findings.

\section{Participants and data collection}

To obtain the interview data a purposive sample of occupational therapy lecturers working in two UK universities was used. The two universities were chosen to obtain a slightly wider range 
of views than would be possible from a single university. Ethical approval for this research was granted by the ethics committee of the School of Education, University of Nottingham.

Permission was obtained from the respective Heads of the occupational therapy departments to contact staff using a staff email list. In total six lecturers from university one and three from university two were interviewed. Written informed consent was obtained from participants based on the aims of the original and more extensive doctoral research.

To protect the anonymity of the interviewees, each lecturer represented in the study had been given a pseudonym and a number, which represented the university they were from and the order in which they were interviewed. For example, 1:1 represents university one, interview 1 and so on. Whereas the purposive sample was based on the experience and knowledge the group offered to this study the selection was made on the basis of convenience and access to this group (Merriam and Tisdell 2015). As the participants were given information on the broad aims of the research to assist with informed consent there was an element of self-selection bias (Robinson 2014). However, the purposive homogeneity of this sample and data collected within a narrative approach values all contributions as valid and credible.

This is a small sample. However, as with most forms of qualitative research, it was more concerned with capturing depth of participants' experience from a small context-specific sample rather than attempting to be representative across the population as a large random sample might claim to be within quantitative research (Crotty 1998). As such it is the transferability of the knowledge produced and how meaningful it is to those in similar contexts which is of importance here rather than any form of statistical significance (Anderson and Herr 2010).

Participants were not asked precisely the same questions, instead they were asked questions under several themes and these questions were reflexively adapted as the interviews progressed. (See interview schedule in table 1). As the interviews were narrative in their design, and the sample purposive, there was a corresponding bias, which is acknowledged, associated with obtaining a meaningful depth of data from the participants experience. This acknowledged bias sees knowledge as co-constructed between the researcher and the 
researched and enhances rigor through the recognition of this relationship through researcher reflexivity (Clandinin 2007). Therefore in-depth and lengthy answers to the questions were encouraged. As a result, many of the responses given by participants are lengthy narrations of their professional experience and views on the subject areas. There were clear similarities across narratives although there were also key differences. All participants were asked if they would like to read through their interview transcripts to check the accuracy of what was recorded but all participants declined.

\section{The insider position and reflexivity}

This paper is taken from doctoral research carried out by the first author as an insider researcher who belongs to the community and organisations researched. Where this insider relationship is crucial is in the interpretations of data and it allows for a deeper understanding of the context within which the research is carried out (Clandinin 2007). Similarly this is reflected in the purposive make-up of the sample and the in depth narrative focus of the interview questions. It is also important to note, however, that the second author is not a member of the occupational therapy profession or familiar with the institutions or academics at the data collection site. As such he was therefore well placed to encourage the first author to reflexively challenge both research methods and interpretations of data. 


\section{Findings}

Four main themes of professional artistry; the professional knowledge language; evidencing practice and neoliberalism and changes to teaching and learning were identified drawn from lecturers' narratives using selected extracts to illustrate the key topic areas. 


\section{Professional artistry}

Professional artistry is key to the way in which occupational therapy lecturers identified themselves as part of the occupational therapy profession. Their identity was underpinned by the profession's values and the expertise they had developed previously as clinicians which they brought into their teaching. It was clear that, for the interviewees, their professional artistry comes from the tacit and implicit combination of knowledge, skills and values which underpin the professional habitus. However, it was noted by some of the interviewees that practice is at risk of being subsumed by the increasing use of check list criteria which might not always relate to client needs. The tension between teaching practices which promote and reflect professional artistry and outcome driven practices appears to be a key factor within the structuring of their professional habitus.

[...] I understand the importance of professional artistry and that importance of and the attributes of the self with a professional knowhow, but also that experiential and practical knowhow in artistry which I think we're so good at... (Jane 3:1).

We can engage people through our professional artistry or people disengage because of a lack of our professional artistry (Jane3:1)

Oh it's gone [professional artistry]. I'm just completely out on a limb I think with that...Every individual has got completely different - so you start with the client you don't start with a piece of paper...and I think, you know, the theory almost is let's get back to what makes people tick, rather than what makes systems (Marion 1:2).

...[S]he's very good as a clinician [a colleague], but has agreed, for example, protocols of care... She's confident enough to step outside those protocols, as an OT, for the benefit of the patient, because she knows that, from what they're saying to her, that protocol isn't working. So she can step outside that. But I can see that maybe other OTs, perhaps less experienced, or because that's the only way they know, would stay in that protocol to the letter. Therefore, I question how does that then link up with our philosophy? Does that challenge, for example, one of our bedrock values around being person centred? I guess it does. So that's one of the things that I find really difficult (Jean 2:1). 


\section{Professional knowledge and language}

Occupational therapy lecturers use of professional knowledge and language within academia was noted as a key part of their identity. This also extended into their wider identity as occupational therapists and as above contributed to the forming of their professional habitus. Theory associated with underpinning occupational therapy practice is key to their identity and this appears to be increasingly supported by the theoretical developments within occupational science and an engagement with critical theory.

... I think we just need to use occupational terms and occupational language and accept ourselves as a very valued profession (Caroline 1:1).

I think occupational science has given extra weight to what we've known all the time since the beginning of the profession. I've certainly found that coming back and teaching reminded me even more strongly than when I did my training of what the values and the core ideas and philosophy of OT are and made me think, yes, that's what we're all about and that's what's really powerful... (Maxine 5:1)

If you compare occupational therapy, education, in some other countries where they have to have longer OT programs because they're working in a wider range of areas, you have to have the critical theory (Geoff 2:2.)

...we need to have more of is the political elements of situating occupation more politically, so that when we look at occupation we look at it in discourses of human rights, (Roz 3:2). 


\section{Evidencing practice and neoliberalism}

These are strong structural drivers influencing occupational therapy lecturers' professional habitus and resulting in changes to practice. There is a sense of professional disempowerment, which is reflected in the theme of professional artistry, and also a need to own the way in which EBP is applied and carried out. This was also expressed as a concern about the types of evidence which are valued when striving for professional legitimacy.

I think one of the things that I worry about...is that, because of this [EBP] externality, it makes their - their inner strength in regards to knowing the way forward, their sense of identity as an occupational therapist, much more - malleable, vulnerable... we need to shift the orientation to be evidence informed practice, in the sense that whilst we are being informed by evidence, we are not being led by it in its totality (Jean $2: 1$ ).

.. there's a kind of tension between how qualitative research is viewed, as opposed to other types of research... the kind of research that you feel stands up in an academic sense and the kind of research that I think OTs - a lot of OTs are more qualitative because that's the way we are with people and that's the way that we approach - understanding how people work in situations and sort of what they want really (Beth 4:1).

So I think we have to be brave enough as therapists and researchers to say look, there's other ways of doing research, there's other methodologies out there we can take ownership of, we can help develop (Jane 3:1).

It meant that we valued, potentially then, our tacit knowledge as practitioners, but we'd got some principles to work from, which were internal to ourselves. Whereas now, the reference point has, I think, tipped the other way and become more external in evidence based practice (Marion 1:2). 


\section{Changes to teaching and learning}

There were some tensions noted between changes to curricula incorporating a business focused language and occupational therapy values but there was pragmatic acceptance of this in order to prepare students for the work place. This was considered challenging to their values as occupational therapy lecturers and a restructuring of their habitus and therefore their ways of doing. Some interviewees noted that changes in teaching and learning required to train students for these new ways of working within the third and private sectors are not currently reflected within OT curricula and that students are not being sufficiently prepared. However there was some agreement that OT lecturers were able to prepare students for these changes.

But maybe in the marketplace is just where all the work is going to be,... I think it's the language, isn't it, I object to... It's nothing about being an OT, it's nothing about using occupation before, but it will be about how people get jobs... (Roz 3:2).

And so the university for me is out of kilter. It's not moving with what's happening now. I mean we're trying to in the undergraduate course, because they are introducing the third sector, but I don't think students are kind a ready for it because it's dammed hard in the third sector on your own (Marion 2:1).

So entrepreneurial, being business-minded, having that acumen to see an opportunity and grasp it, maybe we do, maybe we've got to measure our cost effectiveness, maybe we've got to get more clued up with these models. But I think you'd find a lot of people say I didn't come into the profession for that. So there's that mismatch or there's that stumbling over linguistics or semantics. So maybe we have to spend more time defining what we mean and defining our concepts (Jean 3:1).

Yes, were you looking for some words like flexible, creative, entrepreneurial spirit? Whatever that is. I see it as a little rucksack that they can take and a really good pair of shoes, that they can nimbly jump around, that's how I see it. They've got all the equipment, they're protected, they've got their hat and everything and they can go into the workplace and they can nimbly negotiate it as they can (Nicky 6:1). 


\section{Discussion and Implications}

Professional artistry as a combination of skilful practice, clinical experience, professional values and judgement (Paterson 2005) was expressed as a form of professional capital and intrinsic to professional habitus and ways of doing. This is fundamental to making links within a community of practice and therefore to professional identity and autonomy (Kinsella and Fortune 2016; Whiteford 2009; O'Conner 2006).

However, for some their ability to express their professional artistry was challenged within evidence based practice (EBP) and managerial systems which demand that systematic procedures are followed. As noted by Marion it is the "getting back to what makes people tick" which is key to a compassionate and client centred approach, which although not exclusive to occupational therapy, is fundamental to a professional vocation that aims to work with and for people (Bell 2015; Hocking 2008). This becomes central to maintaining a sense of professional artistry through the use of professional knowledge and language focused on clientcenteredness, holistic practice and humans as occupational beings as the core values which underpin their professional identity.

It was also noted that this professional knowledge and language is increasingly being drawn from a developing body of knowledge coalesced around occupational science (Frank 2012). For most interviewees the key concept of occupation and development of occupational science is a fundamental shift in the way the profession frames and owns its knowledge base and this provides legitimacy. It was also noted by some, however, that this legitimacy must be underpinned by a credible critique of social contexts within which practice occurs and which are compounded by neoliberalism. 
This all plays out within the field of higher education with occupational therapy lecturers' focus on the teaching and learning of students. The use of theory and associated language, underpinned by an emerging body of knowledge, shapes the professional habitus (O'Conner 2006) and, helps to develop professional identity. For occupational therapy lectures the use of an occupational therapy discourse is underpinned by theory, and critique is fundamental to their identity as both occupational therapists and academics. However the use of professional language and knowledge is increasingly being framed within neoliberalism and EBP.

The 'EBP movement' (Hammersley 2013) has tracked the neoliberalist drive within health and social care. On one hand EBP is seen as a rational process for providing evidence, usually framed within a medically focused positivist paradigm, whilst on the other it becomes a commodity to be used and traded by policy makers and managers within health and social care and education (Bell 2015; Clouston 2014; Speed \& Gabe).

This results in an imbalance and a tension between neoliberalist expectations of what constitutes good evidence and the values of professions such as occupational therapy, leading towards a "... dichotomy between its ontological, person-centred approach and the medically dominated constructs..." (Clouston and Whitcombe 2009:314). Although it might be argued that the ontology of the profession is not limited to holistic and client-centred practice, the influence of neoliberalism and EBP on lecturers' practice and on students was evident in most of the narratives. In turn this shaping of the professional habitus by these contemporary factors is influencing occupational therapy lecturer practice resulting in changes to teaching and learning.

Therefore, the prevailing neoliberal discourse appears to be structuring occupational therapy lecturers' thinking and ways of working (Clouston 2014; Kinsella and Whitford 2009. This filters through to the development of students' professional identity through curriculum design and implementation of teaching and learning which reflects this neoliberal discourse. Some of the interviewees suggested that even if they do not agree with these approaches it was necessary to put them into practice so as not to put students and the profession at a disadvantage and therefore acknowledged a pragmatic shift in approaches to teaching and learning. 
However, challenges were noted to the changes in teaching and learning required to train students, for example, these new ways of working within the third and private sectors are not always sufficiently reflected within occupational therapy curricula and as a result students are not being sufficiently prepared. In contrast there was a suggestion that occupational therapists have the ability to respond well to these changes and that occupational therapy lecturers can and do prepare students for the new ways of working.

There is a tension here for occupational therapy lecturers' pedagogical approaches between the types of language and knowledge prevalent within neoliberalism and occupational therapy values. These seemingly opposing positions require careful accommodation within the professional habitus (Artaraz 2006; Conner 2006), to project a clear professional identity.

\section{Limitations}

One limitation was a perspective on gender. Gender is an important feature of occupational therapy professional identity, therefore a different theoretical lens on, for example, the position of occupational therapy in relation to gender representations within a male hegemony, could be an important area of further research.

This study was not directly concerned with the role of occupational therapy lecturers as academics. However, it has been noted that a distinct academic identity might be developing within those occupational therapists employed within academia which would be worthy of further scrutiny. 
The perspectives of occupational therapy clinicians or students were not obtained, however how these changes are viewed by clinicians or students in relation to the occupational therapy curriculum would make for another potential area of further research. 


\section{Conclusion}

One of the key findings, is that neoliberalism and associated polices are influencing the structuring and shaping of occupational therapy lecturer identity towards a business focused approach to teaching and learning. This is mostly due to increased third and private sector involvement and the marketisation and fragmentation of these services, and ways of evidencing practice through EBP. Professional and individual agency is constrained by these structural changes which are shaping occupational therapy lecturer practice. However, mitigating factors are the profession's values, the emerging body of knowledge and, for lecturers, a combination of years of professional artistry and their sense of vocation, built up initially in clinical practice and then transferred into the field of higher education. Although there were varied opinions from the interviewees on what these contemporary factors will mean for the future direction of the profession, there appears to be a pragmatic response to the teaching and learning of students and what they need to know about the contemporary factors, including business focused skills, so they are prepared for the workplace. As occupational therapy lecturers are pivotal in designing and implementing occupational therapy curricula which reflect current work demands on the profession, whilst promoting and developing in students the profession's values, it is crucial that occupational therapy lecturers engage with and critique the contemporary factors which are shaping their professional identity, that of their students and ultimately that of the profession. In doing so occupational therapy lecturers can help to shape a professional habitus which, at its core, reflects the profession's values. Therefore, occupational therapy lecturers' approaches to teaching and learning are key to moving the profession forward in this ever-changing landscape. 


\section{Key messages:}

- Neoliberalism and EBP are shaping occupational therapy lecturer identities within their professional habitus

- Occupational therapy lecturers can critique these factors whilst responding pragmatically to students' requirements.

\section{What this study has added}

Identification of the influence of neoliberalism and EBP on the professional identity and habitus of occupational therapy lecturers and the importance of the profession's values and knowledge in responding to these factors.

\section{Acknowledgements}

Prof. Sarah Speight, Professor of Higher Education, University Associate Pro-Vice Chancellor for Teaching and Learning, Faculty of Social Sciences, for her invaluable contribution as part of the EdD supervisory team.

\section{Research ethics}

Ethical approval was obtained in 2013 (ref. 2013/34/JG) from the ethics committee of the School of Education, University of Nottingham.

\section{Consent}

All participants provided written informed consent to be interviewed for the study.

\section{Declaration of conflicting interests}

The author(s) declared no potential conflicts of interest with respect to the research, authorship, and/or publication of this article.

\section{Funding}

The author(s) received no financial support for the research, authorship, and/or publication of this article. 


\section{Contributorship}

John O'shea carried the original research as part of his Doctorate in Education and Simon McGrath supervised this research. John O'Shea applied for ethical approval. John O'Shea and Simon McGrath contributed to the development of the data, methodology of the project, and the data analysis plan. John O'Shea carried out the data analysis and interpreted the data. John O'Shea wrote the first draft of the manuscript. John O'Shea and Simon McGrath reviewed and edited the manuscript and approved the final version of the manuscript. 


\section{Reference list}

Anderson GL and Herr, K (2010) Generating practitioner knowledge through practitioner action research: moving from local to public knowledge, in Thomson $\mathrm{P}$ and Walker $\mathrm{M}$ (eds.) The Routledge Doctoral Student's Companion: Getting to grips with research in education and the social sciences. Oxon: Routledge, pp. 311-322.

Artaraz K (2006) The wrong person for the job? Professional habitus and working cultures in Connexions, Critical Social Policy, 26(4): 910-931.

BMA (2016) Healthcare delivery structures and funding. London: British Medical Association.

Bell E, Campbell S and Goldberg L (2015) Nursing identity and patient-centredness in scholarly health services research: a computational text analysis of PubMed abstracts 1986-2013, BMC Health Services Research, 15(1): 1-16.

Bourdieu P (1990) The logic of practice. Cambridge: Polity.

Bourdieu P (1998) Practical reason: on the theory of action. Cambridge: Polity Press.

Braun, V and Clarke, V (2006) Using thematic analysis in psychology, Qualitative Research in Psychology, 3(2): 77-101.

Carra KA, Fortune T, Ennals P, D'Cruz K and Kohn H (2017) Supporting scholarly identity and practice: Narratives of occupational therapy academics, British Journal of Occupational Therapy, 80(8): 502-509.

Clandinin DJ (2007) Handbook of narrative inquiry: mapping a methodology. London: SAGE.

Clouston TJ (2014) Whose Occupational Balance is it Anyway? The Challenge of Neoliberal Capitalism and Work-Life Imbalance, The British Journal of Occupational Therapy, 77(10): 507-515.

Clouston TJ and Whitcombe SW (2008) The professionalisation of occupational therapy: a continuing challenge, British Journal of Occupational Therapy, 71(8), 314-320.

Copnell G (2010) Modernising allied health professions careers: attacking the foundations of the professions?, Journal of Interprofessional Care, 24(1): 63-69.

Crotty M (1998) The foundations of social research: meaning and perspective in the research process. London: Allen Lane.

Dingwall R (2008) Essays on professions. Aldershot: Ashgate.

Farias L and Laliberte Rudman D (2016) A Critical Interpretive Synthesis of the Uptake of Critical Perspectives in Occupational Science, Journal of Occupational Science, 23(1): 33-50.

Fortune T, Ennals P, Bhopti A, Neilson, C, Darzins, S and Bruce C (2016) Bridging identity 'chasms': occupational therapy academics' reflections on the journey towards scholarship, Teaching in Higher Education, 21(3): 313-325.

Frank G (2012) 'The 2010 Ruth Zemke Lecture in Occupational Science Occupational Therapy/Occupational Science/Occupational Justice: Moral Commitments and Global Assemblages', Journal of Occupational Science, 19(1): 25-35.

Gabbay, JA and Le May, A (2011) Practice-based evidence for healthcare : clinical mindlines / John Gabbay and Andrée Le May. Abingdon: Abingdon : Routledge.

Hammersley, M (2013) The Myth of Research-Based Policy \& Practice.

Hocking C (2008) 'The Way We Were: The Ascendance of Rationalism', The British Journal of Occupational Therapy, 71(6): 226-233.

Hocking, C (2014) Occupational Therapists Driving Societal Change, The British Journal of Occupational Therapy, 77(12): 591-591.

Kinsella EA and Whiteford, GE (2009) Knowledge generation and utilisation in occupational therapy: towards epistemic reflexivity, Australian Occupational Therapy Journal, 56(4): 249-258. 
Maton, K (2012) 'Habitus', in Grenfell M (ed) Pierre Bourdieu: Key concepts. 2nd ed. London: Acumen Publishing, pp. 48-64

Merriam SB and Tisdell, EJ (2015) Qualitative research: a guide to design and implementation. Fourth edition. edn.

Molineux, M (2011) Standing firm on shifting sands. New Zealand Journal of Occupational Therapy, 58(1): 21-28.

O'Connor, SJ (2007) Developing professional habitus: A Bernsteinian analysis of the modern nurse apprenticeship, Nurse Education Today, 27(7): 748-754.

Paterson, M, Higgs, J and Wilcox, S (2005) The Artistry of Judgement: A Model for Occupational Therapy Practice, The British Journal of Occupational Therapy, 68(9): 409-417.

Paton, C (2014) Garbage-can Policy-making Meets Neo-liberal Ideology: Twenty Five Years of Redundant Reform of the English National Health Service, Social Policy \& Administration, 48(3): 319-342.

Riessman, CK (2008) Narrative methods for the human sciences. London: SAGE.

Robinson, OC (2014) Sampling in Interview-Based Qualitative Research: A Theoretical and Practical Guide, Qualitative Research in Psychology, 11(1): 25-41.

Speed, E and Gabe, J (2013) The Health and Social Care Act for England 2012: the extension of 'new professionalism, Critical Social Policy, 33(3): 564-574.

Sullivan, WM (2000) Medicine under threat: professionalism and professional identity, CMAJ: Canadian Medical Association Journal = Journal De L'association Medicale Canadienne, 162(5): 673-675.

Thibeault, R (2006) Globalisation, universities and the future of occupational therapy: Dispatches for the Majority World, Australian Occupational Therapy Journal, 53(3): 159-165.

Turner, A (2011) The Elizabeth Casson Memorial Lecture 2011: occupational therapy - a profession in adolescence, British Journal of Occupational Therapy, 74(7): 314-322.

Wilding, C and Whiteford, G (2008) Language, identity and representation: occupation and occupational therapy in acute settings, Australian Occupational Therapy Journal, 55(3):180-187. 


\section{Table 1: Examples of themes / topics under which questions were asked:}

- Introductory questions about their journey into becoming an occupational therapy lecturer and their views on this journey in relation to how they see themselves as occupational therapy lecturers and their professional identity.

- What, in their view, constitutes the profession's values, its body of knowledge and how these are contested.

- How types of evidence and knowledge relate to occupational therapy practice and the art of being an occupational therapist

- Their views of research and EBP and how these relate to occupational therapy and the influence they are having on practice in general, on their practice as lecturers and on teaching and learning and course curricula.

- Different types of evidence and knowledge and how or whether these relate to the occupational therapy body of knowledge and values.

- The changes to working practices of occupational therapists and the involvement of the third and private sectors and how this is influencing their practice and approaches to teaching and learning

- How business minded discourse and language are influencing approaches to teaching and learning and whether this is congruent with the values of the profession; how they are responding to this and whether this is changing the way the profession sees itself. 
Table 2: Stages of data analysis.

1. Familiarisation with the data: Following transcription all interviewee transcripts were read through whilst listening to the interviews to ensure accuracy and to get a richer sense of the interviewees' narrative. Transcripts were re-read and the author wrote a short piece based on their initial reflexive thoughts on the participants' narratives.

2. Generating initial codes: All interviewee transcripts were uploaded onto Nvivo and key sections of text coded using the 'Nodes' tool. These codes were derived from the aims of the research, the literature review and the theoretical concept of professional habitus.

3. Searching for themes: Thematic analysis was applied to interview data. Coded data was cross checked using Nvivo 'Explore' to look for tensions and commonalities in the lecturer narratives. The coded data was formed into initial overarching themes made up of several sub themes.

4. Reviewing themes: Interviewee and document data was re-analysed to check that these initial themes were supported by data sets.

5. Contextualising and naming themes: Further analysis and triangulation of data sets was done by contextualising the initial themes within the theoretical framework and the literature review. All stages were iterative, involving going back over the data sets and literature many times, adjusting and refining the themes until the final themes and sub-themes were named.

6. Producing the research report: The final themes were written up under a series of headings which represented the overarching themes followed by a discussion. (Adapted from Braun and Clarke 2006:87). 


\begin{tabular}{|c|c|}
\hline Nodes (coding in Nvivo) & $\begin{array}{l}\text { Themes } \\
\text { • Sub Themes }\end{array}$ \\
\hline $\begin{array}{l}\text { Neoliberalism } \\
\text { OT profession } \\
\text { Teaching and learning } \\
\text { Professional identity } \\
\text { Lecturer identity } \\
\text { Professionalism } \\
\text { Research } \\
\text { EBP } \\
\text { Structure } \\
\text { Theory } \\
\text { Third and private sector } \\
\text { Knowledge and skills } \\
\text { Knofional artistry }\end{array}$ & 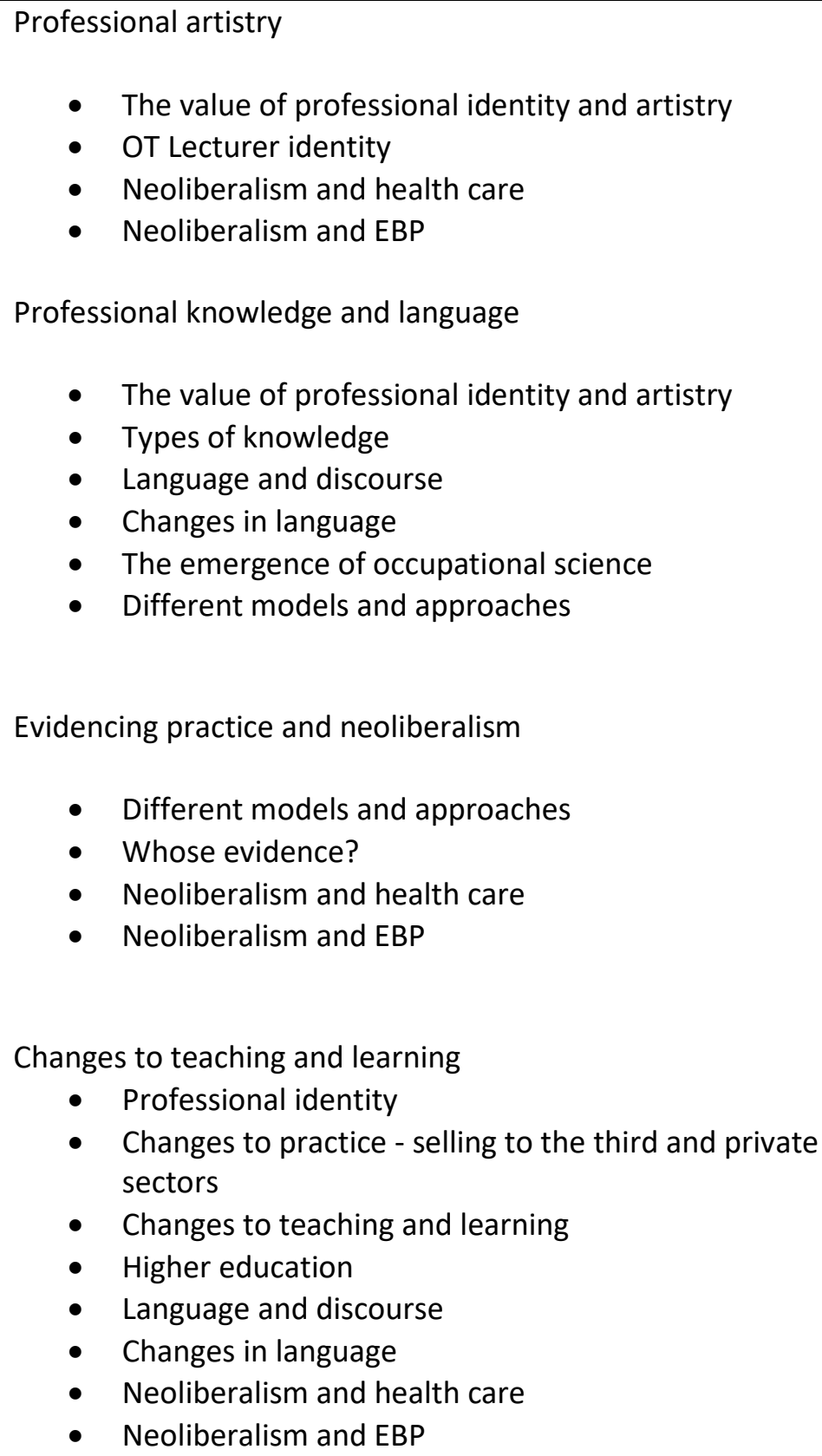 \\
\hline
\end{tabular}

